\title{
Crítica de arte desde la perspectiva de género
}

\author{
Rocío DE LA VILLA ARDURA \\ Universidad Autónoma de Madrid \\ Rocio.delavilla@uam.es
}

Recibido: 5.10 .2013

Aceptado: 24.11.2013

\section{RESUMEN}

La crítica de arte desde la perspectiva de género acorta la distancia con las audiencias. El presente estado de la cuestión analiza a través de once proposiciones cuatro círculos concéntricos: la renovación de la historiografía artística; la erosión del canon y del criterio neutro de calidad; la infiltración de la perspectiva de género en la crítica del arte contemporáneo; y el estado de la crítica feminista en el presente.

Palabras clave: Crítica de arte, género, feminismo, canon, criterios, reconocimiento.

\section{Art Criticism and Gender}

\begin{abstract}
Gendered art criticism shorts the gap with audiences. This status of the issue paper analyzes through eleven proposals four concentric circles: renovation of art historiography; erosion of canon and neutral criteria; gender infiltration on contemporary art criticism; and the estate of feminist criticism at present.
\end{abstract}

Key words: Art Criticism, Gender, Feminism, Canon, Judgement, Recognition

La crítica del arte está definida por su función, desde su origen: la formación de opinión en la esfera pública conformada por los ciudadanos burgueses en los Estados modernos, donde fue decisiva la generación del consenso sobre nuevas experiencias estéticas, estilos formales e iconologías que garantizaran la adhesión de los sujetos a la comunidad mediante gustos y valores compartidos. En tanto su objeto es siempre la actualidad, se encarga de describir, interpretar y valorar lo que es pertinente, de reinterpretar lo que todavía es recuperable y de descartar lo que ya es inapropiado. En palabras de Baudelaire, ha de ser una toma de partido "parcial, apasionada, política", comprometida con la construcción del presente. El éxito del arte moderno y contemporáneo, con sus sucesivas rupturas y alternativas novedosas, está indisolublemente vinculado a la crítica que apuesta por los nuevos movimientos, tendencias y propuestas.

Etimológicamente, proviene de los términos griegos krineín, que significa juzgar; krités, juez; y kritérion, lo que sirve para juzgar. Pero puesto que la propia crítica ha de analizar, establecer y replantear viejos y nuevos criterios, es también 
un ejercicio continuo de autorreflexión, en medio de la incertidumbre. Por ello, las nociones de crítica y de crisis están estrechamente vinculadas: "toda crítica verdadera se da en la modalidad de crisis". De ahí que, en pleno apogeo del reinado de la crítica de arte, en los años veinte del pasado siglo, Walter Benjamin señalara su flanco más vulnerable: "La crítica consiste en adoptar una distancia adecuada y, por lo tanto, se corresponde con un mundo concebido en términos de perspectiva y de proyección en el que era posible adoptar un punto de vista. Ahora, sin embargo, la sociedad se ve presionada por las cosas desde demasiado cerca" ${ }^{2}$. De manera que la crítica quedaría sentenciada precisamente por el desarrollo de la sociedad democrática y mediática que habría contribuido a generar y fortalecer: la inmediatez y el exceso de discurso ${ }^{3}$ anegaría la crítica en la época de la reproductibilidad multiplicada en la pantalla total de Baudrillard. Además, desde entonces, en el ámbito de la cultura y del arte, la institucionalización y la mercantilización crecientes se habrían encargado de desarrollar sus propios "discursos disciplinarios", desembarazándose de la siempre incómoda crítica "distanciada", que parecería haber perdido su "autoridad"4.

Pero, ¿desde qué distancia podría rivalizar con los discursos del poder institucional y mercantil y, al tiempo, de la banalización mediática? No desde la vieja distinción que dictaba presuntamente reglas inmanentes al servicio de la hegemonía y por ello, despierta el resentimiento en la base social ${ }^{5}$. Hoy como ayer, la crítica tiene que servir de mediación social. De manera que quizás sea más relevante hablar de acortar, más que de establecer distancias con la nueva esfera pública ${ }^{6}$; e incluso, de alinearse frente a la denominada "industria cultural", alentando una "contra-esfera pública" vista críticos y comprometidos en su esfuerzo contextualizador y generando dinámicas alternativas para la producción y la gestión, la interpretación y la teoría contemporáneas en conexión con las audiencias 8 .

${ }^{1}$ DE MAN, P. (1991): Visión y ceguera. Ensayos sobre la retórica de la crítica contemporánea, Ed. Universidad, Puerto Rico, p. 12.

${ }^{2}$ BENJAMIN, W. (1928): Dirección única.

${ }^{3}$ SONTAG, S. (1969): Contra la interpretación.

${ }^{4}$ BUCHLOH, B. (2006).

${ }^{5}$ CARRILLO, J. (2003).

${ }^{6}$ ELKINS, J. y NEWMAN, M. (eds.) (2008): The State of Art Criticism, Routledge, Nueva York.

${ }^{7}$ CARRILLO, J. (2003): Crítica de la crítica.

${ }^{8}$ Andrea FRASER ha planteado equivalencias entre la actividad crítica y las prácticas de la sitespecifity, en tanto que el origen de la actividad crítica puede hallarse en una "comprensión crítica" de la audiencia y de su contexto específico. October, "Round Table: The Present Conditions of Art Criticism", no 100, Primavera 2002, pp. 220-228. 
Entre las posturas críticas decididas a acortar distancias, posiblemente, el nuevo punto de vista más relevante en las últimas décadas sea la crítica desde la perspectiva de género que, desde el principio y en su desarrollo está enlazada a las perspectivas de raza, clase, espacio público y ecología que polarizan las tensiones entre la atomización y desintegración social en nuestro mundo global. Se basa en la teoría y el activismo feministas desarrollados en el ámbito del arte y de la cultura visual a partir de la década de los años setenta del siglo XX y, en conjunto, identificado como un movimiento de "resistencia" en el periodo del ultraliberalismo desde los años ochenta del siglo $\mathrm{XX}^{9}$, gracias a su aportaciones y papel aglutinador en las nuevas políticas de representación. Periodo a partir del que se tematiza, primero por Judith Butler y después por Gayatri Spivak la dificultad/imposibilidad de reclamación ante un discurso excluyente. Teorías dirigidas en principio a enfocar los sujetos lesbianos y subalternos, respectivamente; y que vendrían a sumarse a la reivindicación de la diferencia del sujeto de la escritura femenina ya planteada por Hélène Cixous y Luce Irigaray ${ }^{10}$. En conjunto, este sería, en último término el marco de referencia teórico básico para comprender las dificultades de la voz frente al discurso hegemónico de la crítica de arte desde la perspectiva de género.

En un panorama de la historia de la denominada "ginocrítica", cuyo comienzo suele citarse a comienzos de $1970^{11}$ y a lo largo de cuatro décadas, su contribución fundamental ha sido un giro epistemológico que ha hecho tambalearse toda la estructura. La crítica de arte desde la perspectiva de género ha introducido la voz y la mirada de sujetos antes no reconocidos y excluidos del espacio y del discurso públicos (Mulvey, 1975), haciendo que hombres y mujeres cuestionen los supuestos visuales y políticos sobre los que se habían basado sus miradas ${ }^{12}$; ha asignado un lugar a las mujeres como agentes en el espacio de representación, donde antes solo eran representadas; $y$ ha identificado el sexismo inherente en la cultura visual como mecanismo de dominación estructural del patriarcado.

${ }^{9}$ OWEN, C. (1983): ·El discurso de los otros: las feministas y el postmodernismo", en Hal FOSTER, ed., La posmodernidad, Barcelona, Kairós.

${ }^{10}$ Judith BUTLER (1990): El género en disputa. El feminismo y la subversión de la identidad, Madrid y México, Paidós y Universidad Nacional Autónoma de México, 2001.- Gayatri SPIVAK (1999): ¿Pueden hablar los subalternos?, Barcelona, MACBA, 2009.- Hélène CIXOUS (1979): La risa de la medusa, Madrid, Anthropos.- Luce IRIGARAY (1974): Espéculum. Espéculo de la otra mujer, Madrid, Saltes, 1978. Sobre la reflexión de la noción de sujeto, marco para el discurso feminista, vid. Ana MARTÍNEZ-COLLADO (2005): Tendenci@s. Perspectivas feministas en el arte actual, Murcia, CENDEAC; y Asunción OLIVA PORTOLÉS: La pregunta por el sujeto en la teoría feminista, Madrid, Instituto de Investigaciones feministas, UCM.

${ }^{11}$ Se considera texto inaugural el artículo de Linda Nochlin, "Why Have There Never Been No Great Women Artists?", Art News (1971), 69, 23-39, 67-69.

${ }^{12}$ Parafraseo a Jonathan Culler (1982), "Leyendo como una mujer", en Sobre la deconstrucción, Madrid, Cátedra, p. 50. 
Podemos abordar una revisión de sus logros efectivos, de diverso alcance, a través de esta serie de círculos concéntricos: la renovación de la historiografía artística; la erosión del canon y del criterio neutro de calidad; la permeabilidad de la perspectiva de género en la crítica del arte contemporáneo; y el estado de la crítica feminista en el presente.

La ginocrítica ha contribuido a la superación definitiva de la noción viril del genio artístico junto al reconocimiento de la autoría femenina (Battersby, 1989). Con legiones de historiadoras, ha recuperado la amplia producción de miles de artistas, a coleccionistas y críticas que habían sido sepultadas por la historiografía misógina y que están siendo integradas gradualmente en el relato de la historia y de las instituciones museísticas, aunque todavía de manera desigual. Obviamente, la crítica de arte desde la perspectiva de género debe seguir insistiendo en las carencias todavía existentes, sobre todo allí donde son tan notorias como en nuestro país, donde deberían ser más que suficientes argumentos elementales referidos a la equidad social legislada para instituciones públicas -aún detenidas en una burda discriminación sexista- como los museos. Al menos, como dijo Lucy Lippard en 1975, para que a las jóvenes "su progresión no les parezca completamente imposible".

Sin embargo, a pesar de que esta integración en curso ha supuesto la mayor renovación epistemológica en la historiografía artística, son conquistas concretas que a menudo se diluyen en el paradigma del canon y del discurso dominante. Porque la cuestión no reside tanto en "hacer un hueco" en las salas históricas, puesto que las salidas y entradas de autores son más o menos frecuentes en estas instituciones; sino en la erosión del canon, percibida como amenaza por quienes detentan su hegemonía ${ }^{13}$.

El canon es la norma que produce la hegemonía politicosocial y que genera categorías binarias de desigualdad: dentro/fuera; masculino/femenino, alta/ baja cultura, etc., estableciendo una estructura de dominación, exclusión y marginación sobre lo que no está aceptado como norma. Destruir esta concepción del canon obliga a modificar la estructura y a construir nuevas perspectivas sobre la definición, análisis e interpretación de lo artístico.

${ }^{13}$ Según Raymond Williams, "se asegura la hegemonía cuando la cultura dominante utiliza la educación, la filosofía, la religión, la publicidad y el arte para lograr que su predominio les parezca natural a los grupos heterogéneos que constituyen la sociedad”, en Tomas Miller y Georges Yudice (2004), Política cultural, Barcelona, Gedisa. 
Cuestionar el canon es poner en entredicho el relato aceptado, abriendo la posibilidad a plantear nuevas narrativas ${ }^{14}$. Las clasificaciones formalistas, los géneros artísticos tradicionales e incluso las genealogías de maestros y escuelas se ven afectados cuando se evidencian los presupuestos sexistas nunca abiertamente declarados del canon y se pretende otorgar un lugar propio y adecuado a producciones artísticas antes excluidas. En los términos planteados por Griselda Pollock, se trataría de introducir intervenciones feministas en la historia del arte: "Las intervenciones feministas demandan un reconocimiento de las relaciones de poder-género, haciendo visibles los mecanismos del poder masculino, la construcción sexual de la diferencia sexual y el rol de las representaciones culturales en esta construcción" $" 15$.

Un museo o bien una historia del arte que se precie por su excelencia educativa debería disponer de herramientas pedagógicas sencillas para evidenciar la construcción de lo masculino y de lo femenino en la historia visual y el género en el placer visual de la autoría y de sus destinatarios ${ }^{16}$. La supuesta neutralidad de la calidad artística sancionada por el canon no puede seguir sirviendo de vehículo para la asimilación de las viejas estrategias de dominación. La introducción de la crítica desde la perspectiva de género tiene que facilitar la distinción entre el refinamiento formal y el fetichismo, la objetualización e incluso el sadismo inscrito en abundantes representaciones de mujeres en la historia del arte ${ }^{17}$. El ejercicio de la interpretación de la polisemia de lo artístico no puede inhibirse ante su supuesta atemporalidad formal: la interpretación y, por tanto, valoración de las representaciones visuales de cualquier época deben incluir los valores de nuestro presente.

Por tanto, todavía más compleja es la resistencia casi generalizada del sistema de arte contemporáneo a incluir la perspectiva de género como elemento axial y vertebrador. Entonces y ahora, el núcleo del problema radica en la apelación a la neutralidad del criterio de calidad que, en último término, se basa en la noción de "desinterés" en la experiencia estética "pura", según el idealismo trascendental que

${ }^{14}$ NOCHLIN, L. (1971: 2): "Una crítica feminista de la disciplina es necesaria para poder perforar sus limitaciones culturales e ideológicas, revelar diagonales e insuficiencias no simplemente respecto a la cuestión de as artistas mujeres, sino en la reformulación de cuestiones cruciales para la disciplina en su totalidad".

${ }^{15}$ POLLOCK, G. (1988): Vision and Difference, p. 12. La noción de "intervención" también es planteada junto a Rozsika Parker en Framing Feminism (1987). Sobre la trayectoria intelectual y las nociones fundamentales de Griselda Pollock, vid la interesante introducción a cargo de Laura TrafíPrats, en Griselda Pollock (2010), Encuentros en el museo feminista virtual, Madrid, Cátedra.

${ }^{16}$ Vid López Fdez. Cao, Fernández Valencia, M. A. \& Bernárdez Rodal, A. (eds.) (2012): El protagonismo de las mujeres en los museos, Madrid, editorial Fundamentos.

${ }^{17}$ Como ha evidenciado, por ejemplo, Erika Bornay (1998): Mujeres de la Biblia en la pintura del Barroco, Madrid, Cátedra. 
Kant formuló en su Crítica del juicio en 1790. Teoría que ni siquiera en esas condiciones "puras" -y precindiendo de todo "marco"- puede asegurar el consenso intersubjetivo en un gusto determinado ${ }^{18}$. Además, la concepción kantiana admite la más probable experiencia estética "no pura", en la que siempre entra en juego algún interés, como de hecho ocurre en la mayoría de los casos si nos referimos a los espectadores o público y, principalmente, a los agentes implicados en la producción, gestión, distribución y difusión del arte, entre quienes ya se ha demostrado que la cooptación, las oportunidades y el reconocimiento ${ }^{19}$ todavía hoy están sesgados por el género. Porque si, en principio, ni el arte ni el talento tienen sexo, el sexismo sigue campando a sus anchas en el funcionamiento del sistema del arte.

La crítica de arte inclusiva de la perspectiva de género debe evidenciar la discriminación sexista todavía existente y explicitar los motivos y los argumentos ocultos de exclusión en la apelación al criterio neutro de calidad. Tras generaciones de artistas mujeres pertenecientes a las sucesivas oleadas de vanguardias y gracias a las teorías de los feminismos en el arte contemporáneo, la crítica se ha desembarazado de las categorías sexistas que hasta no hace tanto eran de uso ordinario. Vale la pena recordar que hasta la década de los setenta del pasado siglo los estereotipos de lo femenino (delicado, emocional, irracional ..) sojuzgaban la obra de las artistas -aunque estas mismas cualidades fueran sobrevaloradas en el caso de artistas hombres-; así como se consideraba excepcional, en el sentido de desnaturalizado, es decir, de mujeres viriles, cuando su obra se ajustaba y destacaba en el patrón supuestamente neutro. Haciendose ostensible que las indagaciones, normas y criterios planteados por los artistas varones eran asumidos como valores "universales", mientras que los que eventualmente presentaban las artistas -en su aceptación acrítica o bien conscientes del campo acotado que les había sido asignado- eran catalogados solo "de mujeres".

Todavía hoy, lo más frecuente es la omisión de la interpretación, valoración y difusión de la obra de la mayoria -de hecho, existente- de artistas mujeres quienes, sea cual sea su ámbito de trabajo, padecen el olvido de la crítica que se suma a las sucesivas cribas generacionales e institucionales, tal como han demostrado los informes emitidos por el Observatorio MAV en el caso de nuestro país durante la

\footnotetext{
18 “Las 'normas del gusto' son parte de la hegemonía, un medio clave para diferenciar y estratificar la sociedad. El valor proyectado por la hegemonía estética, se basa, en definitiva, en una serie de exclusiones, claramente reconocidas como tales por quienes siempre salen perdiendo" ( $\mathrm{T}$. Miller y G. Yudice, op. cit.).

${ }^{19}$ El primer ámbito para el reconocimiento de la calidad artística se da entre los pares, es decir, entre los propios artistas, vid Nuria Peist (2012).
} 
última década ${ }^{20}$. La crítica de arte, apegada necesariamente al evento del presente, no obstante debe corregir esas ausencias, o su omisión, a causa de la aparente menor relevancia según el rango del espacio expositivo, remodulando la selección de lo que es objeto de la crítica en virtud de la falta de igualdad de oportunidades, si asume la perspectiva de género.

Sin embargo, a diferencia de otros ámbitos, como la crítica literaria en la que es relativamente frecuente que obras de escritoras sean sojuzgadas bajo la etiqueta de "literatura femenina" -que se tilda, desde la misoginia descarada o taimada, destinada solo a lectoras y acompañada de los consabidos tópicos-, en la crítica de arte actual parecen haberse eliminado. Quizás un análisis meticuloso podría rastrear la tendencia de ciertos críticos a prolongar la juventud de las artistas en sus reseñas, o bien la resistencia a explicitar su lugar prominente en la escena contemporánea. Lo más habitual es la ocultación de los criterios sesgados por el género que respaldan su mayor o menor aceptación. Viejos elementos de valoración que han sido eliminados o postergados en la crítica del arte contemporáneo, tipo la (gran) escala o la dificultad técnica sí siguen contando para distinguir en el más alto nivel a las artistas -como puede contrastarse, por ejemplo, en el breve listado de nuestras Premios Nacionales de Artes Plásticas. También es bastante obvia la mayor facilidad para respaldar la obra de artistas mujeres que se inscribe en temas neutros, sin referencia alguna o posicionamiento explícito en una perspectiva de género. O bien, como ya planteó Mira Schor (1991), suele privilegiarse la obra de mujeres que puede adscribirse con facilidad a un "linaje paterno"; así como se oculta, quizá por desconocimiento, la ascendencia "materna" de otras propuestas, sean de autoría femenina o masculina.

Porque la mayor carencia de la crítica de arte en la actualidad es la dificultad, cuando no el rechazo, en asumir un marco teórico de comprensión e interpretación de una producción artística planteada desde la afirmación de la diferencia. Como ya he comentado en otras ocasiones, la falta de herramientas conceptuales para comprender la obra y desgranar su singularidad en ese mapa, el desconocimiento de esa otra tradición o matrilinaje al que responde, la ausencia de criterios apropiados para evaluarla, todo conduce a que el resultado a menudo sea una crítica desenfocada y errática (De la Villa, 2012).

De manera que arbitrariamente, por ejemplo, se acentúa el análisis formalista y elementos estilísticos que son solo subsidiarios mientras se omite la estrategia radical que efectivamente dota de coherencia interna y visual a la obra, en una suerte de elipsis que menoscaba su recepción. La otra posibilidad, consiste en

20 Informes del Observatorio de MAV, Mujeres en las Artes Visuales: http://www.mav.org.es/index.php/observatorio/informes. 
encorsetar el trabajo bajo una etiqueta -"arte feminista", "arte de género", "arte queer"-, pasando de puntillas por cualquier intento de explicación.

La obliteración en la crítica de arte de que la mayoría entre los productores en las últimas generaciones y también entre los públicos son mujeres; o bien, directamente la negación de que este hecho diferencial sea sustantivo en el ámbito del arte y de la cultura son las dos caras de la misma moneda que se introduce una y otra vez en la máquina que escupe privilegios, incluso a raudales, a quienes pertenezcan o no al sexo masculino se encargan de mantener como fieles custodios los valores (implícitos) del viejo patriarcado.

Por otra parte, lo que ha cundido entre gran parte de la crítica es la convicción de que toda producción que de algún modo pueda entenderse vinculada a los feminismos o bien a estéticas comprehensivas del género responden a una irrupción que ya fue y que tiene su capítulo asignado y cerrado en los manuales del arte contemporáneo de la segunda mitad del siglo XX. En realidad, el arte feminista, en sentido lato, desde la década de los setenta no ha dejado de expandirse geográficamente y también a través de la incorporación de nuevas generaciones, tomando nuevas estrategias en sucesivas oleadas, formando más que un ismo o tendencia, una tradición propia que permea el arte contemporáneo. La última oleada, iniciada a partir de 2005 y en continuidad hasta hoy, ha contado con plataformas tan importantes que, por fin, parece haber resquebrajado la guetización a la que estuvo sometida en el sistema del arte contemporáneo (Lebovici, 2008; True Latimer, 2008; De la Villa, 2011).

Grandes retrospectivas, presencia protagonista en las últimas Documenta y principales bienales y la proliferación de exposiciones en destacados museos que han adoptado políticas de género, han obligado a la critica de arte feminista tanto a tener que recapitular sobre la propia tradición -que ahora se retrotrae a la década de 1920 (Pollock, 2008)-, como a indagar nuevas estrategias críticas para dar respuesta a la producción actual cimentada sobre la propia tradición feminista ${ }^{21}$.

El contexto en que surgió y creció la crítica feminista explica que se haya configurado como una tradición que se critica a sí misma como "victimista" y a la vez "celebratoria" o autocomplaciente. La tensión entre ambos polos ha fomentado que la crítica feminista haya sido una perspectiva metodológica en donde la autorevisión así como el debate continuados formen parte de su ejercicio.

${ }^{21}$ Vid, por ejemplo, Bettina Knaup (2011): "Re.act.- vuelven las performances feministas", en Xabier Arakistain y Lourdes Méndez (eds.): Producción artística y teoría feminista del arte: nuevos debates II, Vitoria, CC Montehermoso/Ayuntamiento de Vitoria-Gasteizko Udalak, pp. 114-123. 
Las polémicas han hecho crecer la crítica feminista. Entre las cuestiones que ha afrontado, se encuentran: la posible existencia de una imaginería femenina que, pese a criticada por su implicación biológica, sin embargo ha continuado siendo una vía de interpretación de iconologías y estrategias formales no figurativas ${ }^{22}$; la evidencia del sexismo en las categorías de la literatura artística y la crítica modernas $^{23}$; el antagonismo de las estrategias esencialista y deconstructiva ${ }^{24}$, que protagonizó durante décadas el relato de la genealogía anglosajona, pero que ha quedado finalmente superado tanto en su dimensión cronológica como geográfica en la última revisión ${ }^{25}$; la persistente recusación de la existencia de un estilo de arte feminista; la compleja relación entre arte y posfeminismo, que parece haber sido ya olvidada, en el mismo paquete de las controversias sobre la Posmodernidad $^{26}$.

Desde el inicio, la crítica feminista fue precursora en ocuparse de la diferencia étnica, contribuyendo a la constitución misma y al desarrollo de la teoría poscolonial. Y paralelamente, de la diferencia de género y orientación sexual, abordando el arte lesbiano y sentando las bases para las teorías transgenéricas y queer. Ninguna otra perspectiva metodológica en el ámbito de la crítica y la teoría del arte ha contribuido más decisiva y prolijamente en estos campos. Por otra parte, su contribución también ha sido muy importante en el terreno del nuevo género de arte público como prácticas colaborativas; y en la reflexión sobre la precariedad, desde la cuestión de la gentrificación al precariado en la división laboral de la denominada sociedad del conocimiento.

Las aportaciones sustantivas de la crítica feminista han protagonizado temas centrales para el pensamiento, la cultura y el arte en las últimas décadas: la identidad y el cuerpo y su vulnerabilidad, destacando la cuestión de la violencia de género. Por otra parte, la reflexión sobre lo textual/tejido/redes ha constituido uno de los discursos más completos en la crítica de arte feminista, capaz de enlazar la

${ }^{22}$ CHICAGO, J y SCHAPIRO, M. (1973/2003): "Female Imagery”, Womanspace Journal, n. 3. Lucy LIPPARD (1976) descubre ciertos valores comunes en torno al "foco central", en Prefaces of Women's Exhibitions (three parts).

${ }^{23}$ Un ensayo clásico, Jaudon, V. y Kozloff, J. (1978): "Art Hysterical Notions of Progress and Culture", Heresies n. 4, pp. 38-42.

${ }^{24}$ MEYER, L. (2006): "Power and Pleasure: Feminist Art Practice and Theory in the United States and Britain", en Jones, A. (ed.): A Companion to Contemporary Art since 1945, Oxford, Blackwell, pp. 317-342; De DIEGO, E. (199): "Figuras de la diferencia", en Valeriano Bozal, (ed.): Historia de las ideas estéticas y de las teorías artísticas contemporáneas, Madrid, La balsa de la medusa.

${ }^{25}$ BUTLER. C. (2007): “Art and Feminism: an Ideology of Shifting Criteria”, en Gabrielle Mark, Lisa, (ed.) Wack! Art and the Feminist Revolution, Cambridge y Longres, The MIT Press, pp. 14-24.

26 JONES, A. (1990): El postfeminismo. ¿una vuelta de la cultura de lo femenino?, en Villaespesa, M., ed, 100\%, pp. 198-216. 
recuperación del arte textil en la historia de las mujeres con el debate sobre las estrategias en el ciberfeminismo ${ }^{27}$. Una poética de redes que toma como punto de partida el contacto personal -precediendo a la estética relacional- y colaborativo en el nuevo género de arte público ${ }^{28}$.

Todavía, un dilema de fondo sigue siendo la adopción estrategias, entre la guetización forzada, pero también voluntaria, y la percepción crítica de la posible neutralización derivada de su integración, como vías distintas de entender la diferencia y el objetivo de empoeramiento. También el problema de la pertenencia o no al arte feminista de ciertas producciones quizá pueda considerarse un asunto hasta cierto punto soslayado y abierto a nuevas interpretaciones en "el feminismo por venir", según la reciente recapitulación del momento presente de Griselda Pollock.

La crítica de arte feminista siempre ha intentado escrutar su incidencia efectiva en el sistema del arte mediante diversas vías. Periódicamente, ha emitido autorevisiones sobre el estado de la propia crítica feminista (por ejemplo, Pollock, 1979 y 2008). Por su carácter militante, el análisis sociológico y el diseño e interpretación de estadísticas continua siendo una de sus herramientas ${ }^{29}$. La cuantificación de datos resulta útil tanto para revisar estrategias, como para seguir denunciando la discriminación sexista en el ámbito institucional y ante cualquier foro con responsabilidad política y social.

Por otra parte, el grado de penetración de la propia crítica y teoría del arte feminista en el amplio campo editorial también ha sido objeto de reiteradas revisiones. Si recordamos, por ejemplo, el estado de la cuestión que planteaba Frances Borzello (1995), posiblemente ya se ha superado el "aura de marginalidad" que ligó durante las dos primeras décadas a la crítica feminista con pequeños sellos editoriales. Y aunque esta afortunada liason siga existiendo, posiblemente ya ha sido perforado el techo de cristal de las grandes editoriales, como Phaidon o Taschen, que cuentan con una difusión popular y ahora prácticamente universal. Otro de los problemas que Borzello traía a colación, la posible neutralización del feminismo en la interpretación de grandes figuras también parece hoy minimizado, pues raro es el ensayo, catálogo o biografía de

\footnotetext{
${ }^{27}$ Todavía es recomendable el ensayo clásico de Faith Wilding (1998): "Where is the Feminism in Cyberfeminis?", Paradoxa, 2, pp 6-12.

${ }^{28}$ LACY, S. (ed.) (1995): Mapping the Terrain: New Genre Public Art, Los Ángeles, Bay Press

${ }^{29}$ Un estudio clásico es el incluido en el catálogo de la exposición Making Their Mark. Women Artists Move into the Maintream, 1970-1985, editado por Rosen Brawer, Nueva York, Abbeville Press. En Europa, los estudios estadísticos sobre el medio artístico son parciales y bastante recientes. Para España, consultar los informes del Observatorio MAV http://www.mav.org.es/index.php/observatorio/informes.
} 
artistas o temáticas femeninas que no comprenda algún análisis desde la perspectiva de género y/o feminista; que, por supuesto, es la predominante en relación a cualquier práctica, producción o evento transgender o queer, cuya proyección se ha multiplicado en las dos últimas décadas. La resistencia, sin embargo, se encuentra más bien en los medios de masas.

En cambio, si nos preguntamos por la interpretación de la producción artística realizada por hombres, o bien por la producción artística en general, continúan faltando voces, incluso desde las filas de la crítica feminista.

En cuanto a nuestro país, no será prácticamente hasta los años noventa cuando surja una incipiente historiografía artística desde la perspectiva de género ${ }^{30}$ y poco después, arranque la ginocrítica, a partir de la influyente traducción al castellano de textos nucleares en el catálogo de la exposición $100 \%{ }^{31}$. Si bien la investigación del arte producido por mujeres en la historia de España apenas ha superado el nivel del elenco, a pesar de recuperaciones meritorias ${ }^{32}$, y todavía nos hallamos en el proceso de establecer la genealogía feminista en el arte español del siglo $\mathrm{XX}^{33}$; hoy puede afirmarse que, pese a la pertinaz omisión en la historiografía de la crítica artística en nuestro país, al menos ya se han sentado las bases sobre la propia tradición de la crítica de arte realizada por mujeres y por feministas durante el siglo XX (De la Villa, 2012, 116-119).

${ }^{30}$ Vid La imagen de la mujer en el arte español (1990), Actas de las terceras jornadas de investigación interdisciplinaria, organizadas por el Seminario de Estudios de la Mujer de la Universidad Autónoma de Madrid.

${ }^{31}$ VILLAESPESA, M. (2011): "Por encargo o por provocación”, en Arakistain, X., y Méndez, L., (eds.), Producción artística y teoría feminista del arte: nuevos debates IV, Vitoria, CC Montehermoso/Ayuntamiento de Vitoria-Gasteizko Udalak, pp. 200-209.

${ }^{32}$ El ensayo pionero fue La mujer y la pintura del siglo XIX español, Madrid, Cátedra, 1987, de Estrella De Diego quien, en el prólogo de su reciente reedición hacía un llamamiento a la necesidad de seguir investigando, ante las escasas aportaciones producidas desde entonces. Para una visión general de la revisión del siglo XX en España, vid Rocío de la Villa (2012) "Artistas y arquitectas españolas entre los feminismos, desde 1900 a hoy", Cien años en femenino, Madrid, AC/E - Centro Cultural Conde Duque, pp. 168-193. Aunque hasta ahora el foco de la recuperación se ha puesto, principalmente, en las artistas de la generación de las modernas y posteriormente, en las artistas del conceptual catalán en los años setenta, recientemente se están abordando otros periodos. Vid, p.e., Patricia Molins (2012), La heterogeneidad como estrategia de afirmación. La construcción de una mirada femenina antes y después de la Guerra Civil, y el resto de aportaciones para reconstruir el siglo XX en Mar Villaespesa, ed. (2012), Desacuerdos 7, Centro José Guerrero/MACBA, MNCARS/UNIA, pp. 64-158.

${ }^{33}$ ALIAGA, J. V. y MAYAYO, P (eds.) (2013): Genealogías feministas en el arte español, León y Madrid, MUSAC/This Side Up, con las aportaciones de Olga Fernández, Noemí de Haro, Isabel Tejeda, Assumpta Bassas, Rocío de la Villa y Beatriz Preciado. 
Por otra parte, aunque quedan todavía muchos textos fundamentales de teoría de la crítica de arte feminista en el panorama internacional todavía sin traducir, en las dos últimas décadas se ha multiplicado su acceso online $e^{34}$. Además, ha sido muy relevante el esfuerzo realizado por diversas instituciones para establecer puentes y traer a nuestro país voces principales de la teoría y la crítica contemporánea ${ }^{35}$. A quienes se suma el protagonismo de algunas de nuestras teóricas con influyentes propuestas, como Beatriz Preciado y Remedios Zafra. Y la instigación permanente de la disidencia de género y del análisis y las prácticas subculturales, con las aportaciones liminares en el ámbito de la cultura visual de nombres propios junto a grupos activistas ${ }^{36}$.

En las dos últimas décadas, revistas académicas feministas y no feministas han introducido dosieres y artículos con análisis sobre arte y cultura desde la perspectiva de género y sobre la producción artística realizada por mujeres ${ }^{37}$. Y si bien las revistas generalistas y los influyentes suplementos culturales de los periódicos de tirada nacional tienden a relegar la cuestión, algunas de las principales revistas de arte contemporáneo han dedicado números monográficos a la relación de arte y feminismos ${ }^{38}$.

\footnotetext{
${ }^{34}$ Pionera en esta tarea en España fue la web estudiosonline.net, creada por Ana MartínezCollado en 1997.

${ }^{35}$ Desde el organizado por Erreakzioa/Reacción en Arteleku, Sólo para tus ojos, en 1997 al ciclo Producción artística y teoría feminista organizado por Xabier Arakis y Lurdes Méndez y celebrados de 2008 a 2011 en CC Montehermoso y contnuados en 2012 y 2013 en la Alhóndiga de Bilbao, entre otros centros como CENDEAC, y encuentros y ciclos en museos y universidades. Vid. Cronología en el Centro de Documentación MAV http://www.mav.org.es/cronologiaMAV/cronologia.html; o bien, seminarios http://www.mav.org.es/index.php/the-news/archivo/seminarios.

${ }^{36}$ Me refiero, entre otras, a María José Belbel, Raquel Osborne, Lucas Platero y Fefa Vila, y los grupos LSD, medeak, o maribolheras precarias.

${ }^{37}$ Revistas académicas feministas, ya clásicas como Arenal. Revista de Historia de las mujeres y Asparkía. Investigaciones feministas, junto a otras más recientes como Arte y Políticas de Identidad; Cuadernos Koré. Revista de historia y pensamiento de género; Cuestiones de género: medios de comunicación, publicidad y género; Feminismo e Interculturalidad; Investigaciones feministas; y L.H.A.C.P.G. Lecturas de la Historia del Arte Contemporáneo desde la Perspectiva de Género. A ellas pueden sumarse las revistas dependientes de los Institutos de la Mujer de las Comunidades Autónomas, como de el Instituto Andaluz de la Mujer, con la revista Meridiana y la colección de ensayos Hypatía. Por otra parte, es muy notable el giro dado en última década hacia la inclusión de artículos con perspectiva de género en las revistas académicas de historia y teoría del arte, como Arbor (CSIC) o Espacio, Tiempo y Forma (UNED), entre otras. En todo caso, las revistas académicas suponen un sector minoritario en relación al conjunto de las publicaciones sobre arte, vid el elenco de las 112 revistas de arte que actualmente se publican en nuestro país, confeccionado por la crítica de arte Elena Vozmediano en su blog "Y tú que lo veas", albergado en El Cultural online: Revistas en España, publicado 21 de febrero de 2013.

${ }^{38} \mathrm{Me}$ refiero a las revistas Artecontexto, Exit Book y Exit Express; y en otro orden, ZEHAR. Vid Rocío DE LA VILLA (2012), p. 127, n. 26.
} 
Con el fin de crear una plataforma permanente e influyente, recientemente se ha lanzado la primera revista de arte desde la perspectiva de género online en nuestro país m-arteyculturavisual, con vocación de amplia difusión entre el público de $\operatorname{arte}^{39}$. Un medio con el que intentar equilibrar también un poco la balanza en la difusión y comprensión de los eventos y exposiciones de arte de mujeres y de arte feminista. La rápida consolidación de este medio confirma la existencia de una esfera pública ávida de acortar distancias.

\section{BIBLIOGRAFÍA}

BATTERSBY, C. (1989): Gender and Genius. Towards a Feminist Aesthetics, Londres, The Woman's Press.

BORZELLO, F. (1995): “¿Predicar a los conversos? Las publicaciones feministas sobre arte en los ochenta”, Kathy DEEPWELL ed., Nueva critica feminista de arte. Estrategias críticas, Madrid, Cátedra "Feminismos"/ Instituto de la Mujer/ Universitat de Valencia. pp. 53-61.

CARRILlO, J. (2003): "Crítica de la crítica", M Guasch, (ed.) La crítica de arte, Barcelona, Ediciones del Serbal. pp. 327-341

CHICAGO, J. y SCHAPIRO, M. (1973): "Female Imagery", Womanspace Journal, n. 1, pp. 11-14.

CORDERO R., KAREN y SÁENZ, I. (eds.) (2007): Crítica Feminista en la Teoría e Historia del Arte, México, Conaculta.

DEEPWELL, K. (1998): "La crítica feminista de arte en un nuevo contexto", DEEPWELL, Kathy (ed.) Nueva crítica feminista de arte. Estrategias críticas, Madrid, Cátedra "Feminismos"/ Instituto de la Mujer/ Universitat de Valencia, pp. 19-39.

DE LA VILLA, R. (2003): "El origen de la crítica de arte y los Salones", Anna Guasch, (ed.): La crítica de arte, Barcelona, Ediciones del Serbal. pp. 23-61

DE LA VILLA, R. (2011): "Redes feministas en artes visuales", , Rocío de la Villa (ed.). Agencia feminista y empowerment en artes visuales, Madrid, Museo Thyssen-Bornemisza.

DE LA VILLA, R. (2012): "Críticas y crítica desde la perspectiva de género", ARAMBURU, N., SOLANS P. y DE LA VILLA, R. (eds.) Madrid, EXIT/MAV, pp. 116-127.

FRUEH, J. (1985): "Towards a Feminist Theory of Art Criticism", Arlene Raven, , Costanza Langer y, Joanna Frueh (eds.) Feminist Art Criticism. An Anthology, Nueva York, Icon Edition.

HEINICH, N. (2011): "El reconocimiento en el arte", Xabier Arakistain y Lourdes Méndez (eds.) Producción artística y teoría feminista del arte: Nuevos debates IV, Vitoria, CC Montehermoso, pp. 126-136.

${ }^{39} \mathrm{~m}$-arteyculturavisual www.m-arteyculturavisual.com, fundada por MAV, Mujeres en las Artes Visuales, en octubre de 2012, de periodicidad bimensual. 
LEBOVICI, E. (2008): "Feminismo y falta de contenido", en Xabier Arakistain y Lourdes Méndez (eds.). Producción artística y teoría feminista del arte: Nuevos debates I, Vitoria, CC Montehermoso pp. 24-39.

LINKER, K. (1983): Sexualidad y representación, Sevilla, Junta de Andalucía.

WALLIS, B. (1984), Arte después de la Modernidad. Nuevos planteamientos en torno a la representación, Madrid, AKAL.

LIPPARD, L. (1976): From the Center. Feminist Essays on Women's Art, Nueva York, Dutton Paperback.

LIPPARD, L. (1995): The Pink Glass Swan. Selected Feminist Essays on Art, Nueva York, The New Press.

MAYAYO, P. (2003): Historias de mujeres, historias del arte, Madrid, Ed. Cátedra. MULVEY, L. (1975): "Visual Pleasure and Narrative Cinema", Screen, vol. 16, num.

3, pp. 6-18. Trad. esp. Placer visual y cine narrativo, Valencia, Centro de Semiótica y Teoría del Espectáculo, 1988.

NOCHLIN, L. (1971): "Why Have There Been No Great Women Artists?", Art News, pp. 22-39; reimpresión en Women, Art and Power and Other Essays, Londres, Thames and Hudson, 1989.

PEIST, N. (2012): El éxito en el arte moderno. Trayectorias artísticas y proceso de reconocimiento, Madrid, Abada Editores.

POLLOCK, G. (1988), Vision and Difference, Feminity, Feminism, and the Histories of Art, Londres, Routledge.

POLLOCK, G. (1979): "Feminism, femminity, and the Hayward Annual Exhibition", Feminist Review, n. 2, pp. 33-55.

POLlOCK, G. (1996), Differencing the Canon. Feminist Desire and the Writing of Art's Histories, Londres y Nueva York, Routledge.

POLLOCK, G. (2008): "Desde las intervenciones feministas hasta los efectos feministas en las historias del arte. Análisis de la virtualidad feminista y de las transformaciones estéticas del trauma”, en Xabier Arakistain y Lourdes Méndez, (eds.), Producción artística y teoría feminista del arte: nuevos debates I, Vitoria, CC Montehermoso, pp. 42-63.

RAVEN, A., LANGER, C. y FRUEH, J. (eds.) (1991), Feminist Art Criticism. An Anthology, Nueva York, HarperCollins.

ROBINSON, H. (2001), Feminism-Art-Theory. An Anthology 1968-2000, Oxford, Blackwell. SCHOR, M. (1991), Patrilineage, Art Journal, vol I, num 2, pp. 58-63. Recogido en New Feminist Criticism: Art/Identity/Action (1994), HarperCollins; y en The Feminism and Visual Culture Reader (2003), Routledge; trad. cast. Linaje Paterno, en Cordeo Reiman, K y Saénz, Inda, eds., Crítica Feminista en la Teoría e Historia del Arte (2007).

SHOWALTER, E. (1993): La crítica en el desierto, en Villaespesa, M. (ed.) 100\%, pp. 84-120, Sevilla, Junta de Andalucía, Consejería de Cultura y Medio Ambiente.

VERNET, A, (2010): "Contra la leyenda del arte. Una historia plural y feminista de las artes", en Xabier Arakistain y Lourdes Méndez, eds., Producción artística y teoría feminista del arte: Nuevos debates III, pp. 178-189, Vitoria, CC Montehermoso. 